\title{
Epidemiology and mental disorder: A review
}

\author{
MICHAEL SHEPHERD AND BRIAN COOPER \\ From the Institute of Psychiatry, the Maudsley Hospital, London
}

Though it is now fashionable to speak of the epidemiology of mental illness, this conjunction of terms appeared in the literature only rarely before 1949 , when it was chosen as the title of a conference organized by the Milbank Memorial Fund to explore common ground between psychiatrists and public health workers (Milbank Memorial Fund, 1950). Since then a spate of publications, especially in North America, the Scandinavian countries, and the United Kingdom, has signalized the confluence of two medical disciplines. The number of these investigations is now so large, and their nature so varied, that it is advisable to demarcate the boundaries of psychiatric epidemiology. In Britain this task has been made easier by the cataloguing of current research projects by the M.R.C. Committee on the Epidemiology of Mental Disorder (Rawnsley, 1963a), itself only some four years old. Just over 100 projects are listed, of which approximately one third are focused on the psychological and social aspects of mental illness, either causal or concomitant; about one quarter, which includes genetic studies, are concerned with the incidence or prevalence of different forms of psychiatric morbidity; one sixth concentrate on prognostic or follow-up studies, and almost as many on primarily administrative issues; the remaining small miscellany comprises studies of diagnosis, vital statistics, and the evaluation of therapeutic procedures.

These topics can be taken as representative of the modern view of the scope of the epidemiological method in psychiatry; they fit well, for example, into the outline sketched by Lin in his recent W.H.O. monograph (Lin and Standley, 1962). At the same time, it is apparent that to call the majority of such studies 'epidemiological' is, in one sense, to do little more than attach new labels to old bottles: their objectives have been among the legitimate goals of psychiatric research for over a century. Clearly, some understanding of the evolution of psychiatric epidemiology is necessary if its present status and, still more important, its future prospects are to be assessed.

\section{HISTORICAL DEVELOPMENT}

Many of our current notions on psychiatric epi- demiology were in circulation before 1914, the year in which Goldberger published the first of a series of papers which were to demonstrate beyond argument the professional epidemiologist's contribution to the study of mental illness. There were several welldocumented accounts of the so-called psychic epidemics. The development of intelligence testing and the early studies of suicide had established the value of the ecologist's method; and the older psychiatrists, as Lewis has pointed out, were familiar with such basic epidemiological themes as the relationship between mental disorder and migration, isolation, occupation, and socio-economic change (Lewis, 1962).

In view of these promising trends, it is of more than historical interest to examine the reasons for the relative neglect of the mass aspects of mental disorder in the earlier part of this century. How well the concepts of epidemiology had been established is clear from Frost's masterly review, published in 1927, which summed up the thinking of his day (Frost, 1927). Epidemiology, he wrote, being

'. . . essentially a collective science, its progress is largely dependent upon that which has been made in other fields. Since the description of the distribution of any disease in a population obviously requires that the disease must be recognized when it occurs, the development of epidemiology must follow and be limited by clinical diagnosis, and by the rather complex machinery required for the systematic collection of morbidity and mortality statistics. Epidemiology must also draw upon statistical methods and theory, because even the simplest quantitative descriptions must be stated statistically; and more minute descriptions, involving perhaps the demonstration of complex associations, may require the application of quite elaborate statistical technique. Moreover, quantitative epidemiological descriptions, in terms of frequencies of disease in different population groups, require, as part of their data, more or less detailed statistics of population, implying the prior development of demography.'

Unfortunately, Frost's vision was partially blinkered by the conventions of his day, for he goes on:

$\therefore$ usage has extended the meaning of epi- 
demiology beyond its original limits, to denote not merely the doctrine of epidemics, but a science of broader scope in relation to the mass phenomena of diseases in their usual or endemic as well as their epidemic occurrences. Although it is clear from current usage that the definition of epidemiology has been extended beyond its original sense, it is not clear just how far it has been extended. It is certain that its scope is not usually limited to the diseases in which epidemics are characteristic, since it is entirely in conformity with good usage to speak of the epidemiology of tuberculosis; and it seems customary also to apply the term to the mass phenomena of such non-infectious diseases as scurvy, but not to the so-called constitutional diseases, such as arteriosclerosis and nephritis ...

'In this sense epidemiology may be defined as the science of the mass phenomena of infectious diseases, or as the natural history of the infectious diseases.'

In as much as this definition would exclude most mental illness from the purview of the epidemiologists, their disregard of psychiatry - with some rare and distinguished exceptions - could be attributed to the state of development of their subject. The failure of their leading psychiatric contemporaries to interest themselves in the mass phenomena of mental illness, on the other hand, can be more readily explained in terms of professional priorities. Many psychiatrists were preoccupied with a set of biological and phenomenological concepts, hoping to establish a scientific nosology with, in Adolf Meyer's words, 'the psychological facts in their patients as mere symptoms of more or less hypothetical diseases back of them' (Meyer, 1912). Yet to the more discerning epidemiologists these 'psychological facts' were inseparably part of the mass phenomena of mental disorder; to Greenwood, for example, they figured prominently among his procatarctic factors of disease and he wrote of them with characteristic hard headedness: 'It is my business to point out that while a fairly consistent description of the aetiology of such crowd-diseases . . . can be provided by means of the hypothesis that the psychological element in the mixture of interactions expressed in bodily illness is the determinant, methods which have ignored that element have led to no consistent account of the facts at all. For this severely practical reason $I$ hold that practical epidemiologists cannot afford to neglect psychology. What psychology they should study is not for me to say.' (Greenwood, 1935).

Thirty years later, it is easier to appreciate that for the epidemiologist, concerned primarily with the study of populations, a meaningful psychology must extend beyond the individual organism. Unfortunately such a psychology was lacking a generation ago. Meyerian commonsense psychology, shaped by its originator's interest in the social sciences an construing mental illness as 'the reaction of a pez sonality (conceived as made up of constitutiona endowment plus experience) to a situation in the social environment' (Leighton, 1951), might have provided an acceptable theoretical system had it not been for the clumsiness of most psychobiologicaf formulations. At the same time, attempts to frame theory of group behaviour based on instinctual prov. pensities (Trotter, 1942) became submerged by the growing influence of Freudian psychology, and were: to remain neglected until the contemporary renewais of interest arising from comparative ethology. In his discussion of group psychology Freud gave luciof. expression to the latent antithesis between his ow outlook and that of the social psychologist:

$\stackrel{8}{2}$

'Group psychology is . . . concerned with the individual man as a member of a race, of a nation or as a component part of a crowd of people who. have been organized into a group at some particula $\vec{\omega}$ time for some particular purpose. When once natura? continuity has been severed in this way, if a breach is thus made between things which are by nature interconnected, it is easy to regard the phenomena which appear under these special conditions as beith expressions of a special instinct ("herd insting्ष्ठ" "group mind"), which does not come to light in an\$ other situations. But we may perhaps ventureoto object that it seems difficult to attribute to the fapos of number a significance so great as to make capable by itself of arousing in our mental life a mew instinct that is otherwise not brought into play. Gur expectation is therefore directed towards two on possibilities, that the social instinct may not be primitive one and insusceptible of dissection, an $\$$ that it may be possible to discover the beginnings of its development in a narrower circle, such as that of the family' (Freud, 1955).

While this point of view does not preclude a interest in the mass phenomena of disease, the emphasis of so authoritative a theorist tended to produce a concentration on individual psychopathology at the expense of a psychology of socia involvement. Indeed, as one sympathetic critic has. observed: 'With certain exceptions, social pyscholog and psychoanalysis do not contradict each otherthey no longer speak the same language' (Brown 1961). Linguistic difficulties can be expected to inis pair communication. It is therefore not surprising that misunderstandings arose between epidemio logists and depth psychologists over questions of mutual interest. Psychodynamic embellishments, fo example, lent a baroque facade to the severe outlines: of the notion of accident proneness; and pyschof analysts have tended to show so little regard for thes ecological approach to suicide that as late as the 
mid-1930s one of their most prominent representatives could claim that '. . . statistical data on suicide as they are compiled today deserve little if any credence' (Zilboorg, 1936).

But if the growth of epidemiological psychiatry between the wars was retarded by these circumstances, a few investigators were able to anticipate the subsequent renaissance. Far-sighted workers in the public health field, like Greenwood and Wilson, initiated collaborative studies with psychiatrists. Some psychiatrists-E. O. Lewis in Britain, Brugger in Germany, Rosanoff in the United States-affirmed their concern with public health aspects of their work by conducting large-scale community surveys (Lewis, 1929; Brugger, 1931; and Rosanoff, 1917); while others were led to the same field of study by an interest in genetics (Strömgren, 1950). In America statisticians like Malzberg and Pollock made use of data compiled in mental hospitals (Malzberg, 1940; Pollock, 1925), and sociologists of the Chicago school began to study the urban ecology of mental illness (Faris and Dunham, 1939; Robinson, 1950). Scattered, uncoordinated, and deriving inspiration from several disciplines, these studies paved the way for the rapid expansion which was to follow the Second World War.

The rapidity of this expansion owed something to the unprecedented interest taken in the mental health of both the military and civil populations during the conflict. Its chief impulse, however, came from the post-war renewal of interest in the psychosocial components of morbidity and the emergence as a separate discipline of social, or 'comprehensive', medicine. Epidemiological methods are fundamental to the aims of social medicine, which stands or falls by the ecological approach to illness-and especially to non-infectious, chronic illness where mental diseases take their natural place among Ryle's 'diseases of prevalence, which also have their epidemiologies and their correlations with social and occupational conditions, and must eventually be considered to be in greater or less degree preventable' (Ryle, 1948). Already in 1944 the Goodenough Report had underlined the importance of social medicine for British psychiatry; and what we now term social psychiatry has flourished to the point of pre-eminence in this country. The working assumption of the social psychiatrist is contained in Morris Ginsberg's statement that: 'Though the individual consists largely of his social relations, there is a core of individuality in each person which is uniquely his own and which is in the last resort unshareable and uncommunicable' (Ginsberg, 1956). It is an assumption which harmonizes not only with the undogmatic eclecticism of British psychiatry but also with the philosophy of the National Health Service in a welfare state where the conflicting claims of the citizen and his society constitute a basic political issue.

\section{PROBLEMS OF METHOD}

An historical perspective, then, however limited in scope, can elucidate some of the reasons for the recent upsurge of interest in epidemiological psychiatry. It also helps to account for the comparatively meagre success so far attained. But this relative failure cannot be fully understood without reference to the factors which limit the application of epidemiological methods to mental disease. The limitations spring partly from a lack of basic information which time and effort can be expected to supply; but over and above these remediable deficiencies are more intractable problems; for convenience these may be subsumed under two main headings, the causation of mental illness, and the classification and measurement of psychiatric disorders.

THE CAUSATION OF MENTAL ILLNESS To some modern epidemiologists, there are no a priori grounds for regarding mental illness as qualitatively different from other types of morbidity, so that the same tools which have proved so efficacious in the study of organic disease can be readily adapted to that of psychiatric disorder. Thus Reid comments that ". . . many mental illnesses are as much "crowd diseases" as is typhoid fever', and again: 'Although these (epidemiological) models were designed to fit the behaviour of infectious disease, there is no reason why some appropriate forms should not apply to the aspects of crowd behaviour, such as the dissemination of psychological disorders in human populations' (Reid, 1960).

This viewpoint overlooks some important aspects of psychiatric disorder, which are discussed in a report of the W.H.O. Expert Committee on Mental Health (W.H.O., 1960), and can be summarized as follows: First, there are individual factors in the causes and manifestations of many psychiatric diseases which, because they belong to the sphere of values, cannot be fully quantified. Secondly, the aetiology of mental disorder is essentially multifactorial in nature. Thirdly, there are considerable social and cultural differences in what is considered psychically abnormal in different surroundings, and in the way such abnormality is treated. Finally, human character and behaviour deviations show infinite variation, ranging from severe psychosis to mild personality disorders which many would regard as outside the boundaries of psychiatry.

In practice, mental illness is rarely infective, but it is often communicable. The extensive literature on 
mass outbreaks of irrational behaviour, extending from the so-called psychic epidemics to the more sophisticated modern studies of 'socially shared psychopathology' (Gruenberg, 1957), testifies to the interest taken by many workers in the nature of this communication. Penrose has made a spirited attempt to retain the classical triad of host, environment, and agent in his mathematical model of crowd behaviour, with the morbid or exaggerated idea in the role of noxious agent (Penrose, 1952). For most workers, however, the causes of abnormal group behaviour are to be sought in the reactions of more or less predisposed individuals to particular sets of physical, psychological, or social circumstances. On this point there is agreement between attempted explanations otherwise as far apart in time and spirit as Hecker's 'sympathy' or 'imitation' (Hecker, 1859). Durkheim's 'collective disposition' (Durkheim, 1951), and Kräupl Taylor's 'pluralistic emotions' (Kräupl Taylor and Hunter, 1958).

This emphasis on host-environment interaction is carried over in the epidemiological approach to the large mass of non-infectious and non-communicable psychiatric illness even when a physical agent like alcohol can be identified. Traditionally the study of factors pertaining to the host has been the domain of genetics, with a large contribution from epidemiology. Recent developments in genetics, to which reference is made later in this article, have brought the two disciplines still closer and if, as Böök has recently asserted, the geneticist must now $\therefore .$. ask the question "what does the gene do to this individual" in the same sense as the virologist inquires about the effect of a specific virus' (Böök, 1961), then the prospects of collaboration are closer still.

For the moment the epidemiologist's primary concern is with the influence brought to bear on the phenotype at different epochs of the life span. In the earliest paranatal phases of development the influences are dominantly physical; as the organism undergoes 'psychosocial evolution', to borrow Medawar's phrase, so the social environment becomes increasingly important and the epidemiologist turns naturally to his colleagues in the social sciences for help. From them he has already received, and made good use of, such conceptual tools as class, mobility, isolation, and kinship; and when the delineation of social systems assumes primary importance, as with some forms of delinquent behaviour, the contribution of the social scientist becomes crucial. Unfortunately, however, the social sciences are still handicapped by what T. H. Marshall terms 'a relative shortage of apparatus', which makes it difficult to '. . provide schemes of analysis by which complicated problems are reduced to simple formulae' (Marshall, 1963). Until these formulae become available the epidemiological study of socia and interpersonal events, and the subject's percep tion of them, will remain gravely handicapped.

CLASSIFICATION OF PSYCHIATRIC DISORDERS The epidemiologist must identify his cases before he can count them, and he should be able to define an classify what he identifies. The nature of mos psychiatric disorders, however, is so ill-defined as to preclude an aetiological classification. Within th $\overrightarrow{\vec{C}}$ major functional psychoses diagnostic practices have been shown to differ widely (Kreitman, 1961). Varia tion is even more pronounced among the minor dis orders, where the inadequacy of current systems of classification is most exposed. Estimates of the amount of neurotic illness dealt with by generaw practitioners, for example, have varied widel $\vec{b}$ (Kessel and Shepherd, 1962) and Crombie has pointed out that the International Classification of Disease does scant justice to the psychiatric case load in general practice, whose importance he has indicated by proposing a fivefold subdivision of totai morbidity into (i) an illness, all or nearly all organic (ii) an illness, mainly organic, but with some enfor tional content; (iii) an illness with emotional a organic components in equal proportion; (iv) $\frac{P}{\mathrm{Q}} \mathrm{P}$ mainly emotional illness but with some orgapic content; and (v) an illness all or nearly all emotion (Crombie, 1963).

Along with the task of classifying declare morbidity goes that of identifying and classify mentally ill persons who do not seek medical social care. This ill-defined zone of disability is popu lated not only by individuals who exhibit psychoo logical symptoms, anomalies of behaviour, and deviant personality traits, but also by those who faib to meet the 'social-cultural expectations' (Zubin 1963) of their social group, and so demand assess $\triangle$ ment within a particular social context. The principa 5 case-finding instruments available today are psychiatric and structured interviews, psychological screen ing tests and scales, and ratings of social adjustmento to family, peers, work, and community (Blum, 1962) For none of these methods is there at present ade quate information as to reliability, validity, stabilityo over time, or the importance of cultural factors in determining the accepted norm.

Uncertainties of diagnosis are closely linked to the problem of measurement. Mortality rates cannoto often be applied usefully to psychiatric disorders, though when they are relevant, as in the case of suicide and of general paresis, they have been employed to good effect. Traditionally, the morbidityo statistics for mental illness have been derived fromn mental hospital records, and first admission rates N 
have provided a valuable guide to the incidence of major psychotic illness. Outside hospital practice, the records of industrial sickness absence and of general practice consultations have made it possible to use spells of sickness and doctor-patient contacts as indices of morbidity. By and large, however, the chronic, fluctuating course of much minor psychiatric disability places a heavy strain on the customary units of measurement. Duration may be difficult to determine, and operational measures such as 'episodes' of illness are not easily defined. The definition of illness proposed by Hinkle and Wolff, for example, as 'any symptom or syndrome that the American medical profession at the present time generally accept as evidence of ill-health' (Hinkle and Wolff, 1957), can be commended more on patriotic than on scientific grounds. More complex indices such as the 'lifetime prevalence rate' are correspondingly less precise. The epidemiologist is thus seriously handicapped in his efforts to measure the rates of specific disease groups or reactions, and in the past he has tended to use global estimates of mental disorder, often lumped together with the rates for suicide, juvenile delinquency, crime and divorce, as catch-all indices of mental ill health. The case remains unproven for bringing together such disparate items on a linear scale to estimate the sickness of a society.

\section{APPLICATIONS OF THE EPIDEMIOLOGICAL METHOD TO} PSYCHIATRY

This chequered background helps to explain why it is more informative to dwell on the uses rather than the achievements of the epidemiological method in psychiatry. Morris has suggested that there are seven uses for epidemiology, namely, for historical study, for community diagnosis, for study of the working of health services, for estimating the individual risks of acquiring disease, for completing the clinical picture, for identifying syndromes, and for establishing the causes of illness (Morris, 1957). These several uses are, as he admits, no more than variations on a single theme, the 'study of the health and disease of populations and groups in relation to their environment and ways of living'. The spectrum of these seven variations passes from scientific analysis to public health action; each in turn can now be considered in relation to mental illness, the connexions being illustrated with relevant examples.

AETIOLOGICAL STUdies The primary scientific business of epidemiology is to do with the aetiology of disease, and its techniques are especially useful in assessing the relative importance of multiple causes. After nearly 50 years the studies of pellagra by Goldberger and his associates remain the most convincing demonstration of the value of this method applied to a neuro-psychiatric condition; or, to be more precise, of the method in the right hands, for it is not always recalled that the Thompson Commission, working at the same time on the same problem with the same methods, reached radically different conclusions (Siler, Garrison, and MacNeal, 1917). Goldberger himself summed up the essence of his work as follows when he pointed out that to suggest a faulty diet as the root cause of pellagra was also to draw four inferences. 'These are', he wrote, 'first that a difference in diet as between pellagrins and non-pellagrins be demonstrable; second, that the disease must be curable by a proper diet; third, that it must be preventable by such a diet, and, fourth, that it may be experimentally produced by diet' (Goldberger, 1927). The establishment of these four postulates, and the coincident eradication of a major scourge, constitute one of the most remarkable achievements in modern medicine, whose details unfortunately still lie buried in the archives of the U.S. Public Health Reports, and merit much wider publicity. From the original accounts it is clear that although he was dealing with a condition in which the deficiency of a physical factor was both a necessary and sufficient cause, Goldberger was also alert to not only the massive socio-economic role of poverty in pellagra but also to the more subtle part played by psychological factors. Thus, in his first paper he suggested that, contrary to popular belief, pellagra was unlikely to be a communicable disease because of the exemption of nurses and attendants in mental hospitals where the disease was rife among the inmates. He commented drily: 'The writer from personal observation has found that although the nurses and attendants may apparently receive the same food, there is nevertheless a difference in that the nurses have the privilege, which they exercise, of selecting the best and greatest variety for themselves. Moreover, it must not be overlooked that nurses and attendants have opportunities for supplementing their institutional dietary that inmates as a rule have not' (Goldberger, 1914). Again, on the appearance of deficiency symptoms among some residents of $\mathbf{S}$. Carolinian villages with adequate food supply, Goldberger wrote as follows: "A great variety of causes may operate to bring about individual peculiarities of taste with respect to food. They may have their origin in the seemingly inherent human prejudice against the new untried food or dish; they may date from some disagreeable experience associated with a particular food; they may arise as the result of illadvised, self-imposed or professionally directed dietary restrictions in the treatment of digestive disturbances, kidney disease, etc.; they may originate as a fad; and in the insane they may arise because of 
some delusion such as the fear of poisoning, etc. (Goldberger, Wheeler and Sydenstricker, 1920).

All subsequent experimental studies, including the recent work on the inborn metabolic error of Hartnup's disease (Hersov and Rodnight, 1960), have served to confirm and elaborate on the broad picture of pellagra as defined epidemiologically. To be sure, the disease lent itself to this approach: it was well described clinically; the proximate causes were concurrent; and individual variation was relatively small. Goldberger himself was aware of these advantages and correspondingly cautious about the prospects of epidemiological research in other, more obscure, mental illnesses. Declining an offer to undertake research into schizophrenia, for example, he wrote: ' . . in five or more years I could probably find out nothing. Much work will be needed on the physiology of the central nervous system and on many collateral problems before dementia praecox can be understood' (Parsons, 1943). Time has proved him right. A recent review of the epidemiological contributions to our knowledge of psychiatric aetiology suggests that the volume of work is more impressive than its results (Milbank Memorial Fund, 1961).

The quest for causes has, in general, been directed towards the establishment of associations between significant events in the life history and the subsequent appearance of mental illness. These events can be subdivided chronologically into those with effects which are delayed in time, and those which are close enough to the outbreak of illness to be regarded as proximate or precipitant. The latter group has lent itself to population studies most conveniently in times of upheaval. Rawnsley, for example, has assessed the mental bealth of the Tristan da Cunha community evacuated to this country after the volcanic eruption in 1961 and has been able to compare his findings with those of a Norwegian expedition which visited Tristan in 1937-38 (Rawnsley, 1963b). The outstanding feature described by the Norwegians had been an outbreak of hysterical spells among the women of the island; the 19 survivors with a history of these 'spells' were shown 25 years later to exhibit higher recent medical consultation rates and, in particular, to suffer from a form of psychogenic headache, which, in turn, proved to be significantly more often present among the wives of the island's leaders. Table I represents Rawnsley's attempt to relate the two indices of morbidity, i.e., an earlier hysterical 'spell' and a psychogenic headache, to the social factor of status: though the numbers are too small to be conclusive they suggest strongly that the paired associations are independent of the remaining variable.

For the study of proximal precipitants under more
TABLE I

RELATIONSHIP BETWEEN PSYCHOGENIC HEADACHE, HYSTE疋 ICAL CASES (1937), AND SOCIAL POSITION IN THE TRISTAO DA CUNHA COMMUNITY

Leaders' Wives Controls

1937 Cases Non-cases 1937 Cases Non-cases

\begin{tabular}{|c|c|c|c|c|}
\hline $\begin{array}{l}\text { Psychogenic headache } \\
\text { Other symptoms }\end{array}$ & $\begin{array}{l}9 \\
1\end{array}$ & $\begin{array}{l}5 \\
8\end{array}$ & $\begin{array}{l}2 \\
1\end{array}$ & $\begin{array}{r}4 \\
16\end{array}$ \\
\hline
\end{tabular}

normal conditions Gordon has emphasized the value of analysing infrequently occurring, single events, $b$ analogy with point epidemics, and has exemplifiee his argument with the psychoses after childbirt (Thomas and Gordon, 1959). His suggestion has been followed up by Paffenbarger, who, by examining area hospital records over an 18-year period, idente fied a group of women whose first mental illness ha: occurred in relation to childbearing; 125 post-partum; psychoses were detected, comprising a first-attack rate of 0.7 per 1,000 live births (Paffenbarger, 1961) $\overrightarrow{\mathrm{cos}}$ A control group was derived from women of the same race whose deliveries immediately preceded of followed those of the index subjects. The two group? were compared in respect of age, parity, age at marriage, social class, period of gestation, bimitid weights, and the somatic complications of pregna and parturition. The small numbers involved limited detailed comparison, but there was a definite tendency for the frequency of recorded somatis complications to differentiate between the two groups. To test the specificity of these findin Paffenbarger went on to make identical comparisons with two other index groups, namely, mothers wis had developed late post-partum haemorrhage, $\underset{\vec{n} d^{\mathbb{P}}}{ }$ mothers whose infants had developed hypertrophig pyloric stenosis. In neither were the differences of the same order as those found with the psychotic mothers.

Essentially the same method of retrospective analysis of hospital records has been employed by Pasamanick and his co-workers to examine the sig응 nificance of much earlier events in the individual lifehistory. They collected information about the com? plications of labour recorded on birth certificates or hospital records, and compared the data obtained. with those relating to infants selected from the same batch of birth certificates and matched for a number of relevant variables. The logic of this procedure, in the authors' own words, runs as follows:

'(1) Since prematurity and complications of pregnancy are associated with foetal and neonatal death,? usually on the basis of injury to the brain, there must remain a fraction so injured who do not die. (2) Depending upon the degree and location of the damage, the survivors may develop a series of disorders. These extend from cerebral palsy, epilepsy, 소 
and mental deficiency through all types of lesser degrees of damage sufficient to disorganize behavioural development and lower thresholds to stress. (3) Further, these abnormalities of pregnancy are associated with certain life experiences, usually socio-economically determined, and consequently (4) they themselves and their resulting neuropsychiatric disorders are found in greater aggregation in the lower strata of our society' (Knobloch and Pasamanick, 1960a).

The use made of this method is illustrated most clearly by reference to mental subnormality, one stage along their "continuum of reproductive casualty'. Their retrospective studies had suggested a significant association between subnormality and not only such physical features as prematurity, maternal complications of pregnancy and neonataabnormalities, but also socio-economic status, race, and season of birth. To assess the individual importance of these several factors the authors then resorted to a prospective study, following up 500 premature babies and a control group of full-term infants matched for hospital of birth as well as for socio-economic circumstances (Knobloch and Pasamanick, 1960b). At forty weeks the premature infants exhibited a higher incidence of neurological abnormalities and a lower development quotient on the Gesell development examination. These findings were confirmed when 300 of the children were reexamined more than two years later, but in addition it was then noted that whereas at forty weeks the development quotients of white and coloured control children were virtually identical the groups had diverged by the age of 3 years. Table II shows that whereas the white children then exhibited an improvement of their adaptive and language skills, the opposite was true of the negroes. The sharpest decline was recorded for the children whose mothers had received the poorest education. These differences, which were not evident in other fields of behaviour, are attributed by the authors to socio-cultural factors.

\section{TABLE II}

COMPARISON OF DEVELOPMENTAL QUOTIENTS AT 40 WEEKS AND 3 YEARS OF AGE IN FULL-TERM INFANTS BY RACE (BALTIMORE, MARYLAND, 1952-1953)

Developmental Quotients

\begin{tabular}{lrrrr}
\cline { 2 - 5 } Age at examination & \multicolumn{2}{l}{40 Weeks } & \multicolumn{2}{l}{3 Years } \\
\cline { 2 - 5 } Race & White & $\begin{array}{l}\text { Non- } \\
\text { white }\end{array}$ & White & $\begin{array}{l}\text { Non- } \\
\text { white }\end{array}$ \\
\hline $\begin{array}{l}\text { No. of cases } \\
\text { Field of behaviour general } \\
\text { (adaptive) }\end{array}$ & $(223)$ & $(269)$ & $(77)$ & $(82)$ \\
Gross motor & 105.4 & 104.5 & 110.9 & 97.4 \\
Fine motor & 114.7 & 113.4 & 113.7 & 112.5 \\
Language & 97.6 & 99.2 & 100.7 & 98.6 \\
Personal-social & 102.5 & 102.9 & 106.0 & 90.1 \\
& 108.6 & 106.5 & 110.5 & 106.8
\end{tabular}

Longitudinal studies of this kind, in which a cohort of normal subjects is followed up in order to define variations of development, and so to assess the significance of deviant behaviour, represent an epidemiological technique of increasing importance. Other examples include the study by Douglas of a national sample of British children born during one week in 1946 (Douglas and Mulligan, 1961), and Mangus and Dager's survey of factors related to personality change in the second decade of life (Mangus and Dager, 1959). The information provided is especially valuable for child psychiatry which has long suffered from the lack of normative data against which to evaluate supposed disorders of behaviour. These studies, however, are slow to mature and can be usefully supplemented by crosssectional surveys. In the Bucks Child Health Survey, for example, data have been collected about a $10 \%$ sample of all school-children between the ages of 5 and 15 in an English county (Shepherd, Oppenheim, and Mitchell, 1964b). Figure 1 shows the reported frequency distribution, by age and sex, of bedwetting, a common cause of referral to child guidance clinics. There stands out a small but persistent group of daily bedwetters up to the age of 10-11, most of whom were receiving no medical attention, and were not regarded as presenting psychiatric problems.

As an aid to the study of human development, epidemiology helps to assess the impact of life experiences on innate characteristics. The newer technical advances have now made possible the extension of epidemiological research into the field of genetics proper. In mongolism, for example, Cohen et al. have pointed out that the newly discovered chromosomal abnormalities have already made it necessary to estimate (1) the chromosomal constitution of a representative sample of phenotypically normal subjects; (2) the comparative incidence of mongolism, in order to examine the effect on non-disjunction of external events like ionizing radiation; (3) the possible association between trisomy and translocation and maternal age; and (4) the relationship between mongolism, leukaemia, and ionizing radiation (Cohen, Lilienfeld, and Sigler, 1963). All these questions are open to a form of epidemiological study which can be expected to proliferate in the wake of other cytogenetic discoveries.

ILLNESS-EXPECTANCY STUDIES Estimating the individual expectation of psychiatric illness has also been a joint concern of genetics and epidemiology. Some of the outstanding early investigations of mental disorder in communities were inspired by a primary interest in genetics, and indeed Fremming, whose longitudinal study of mental illness on the island of 


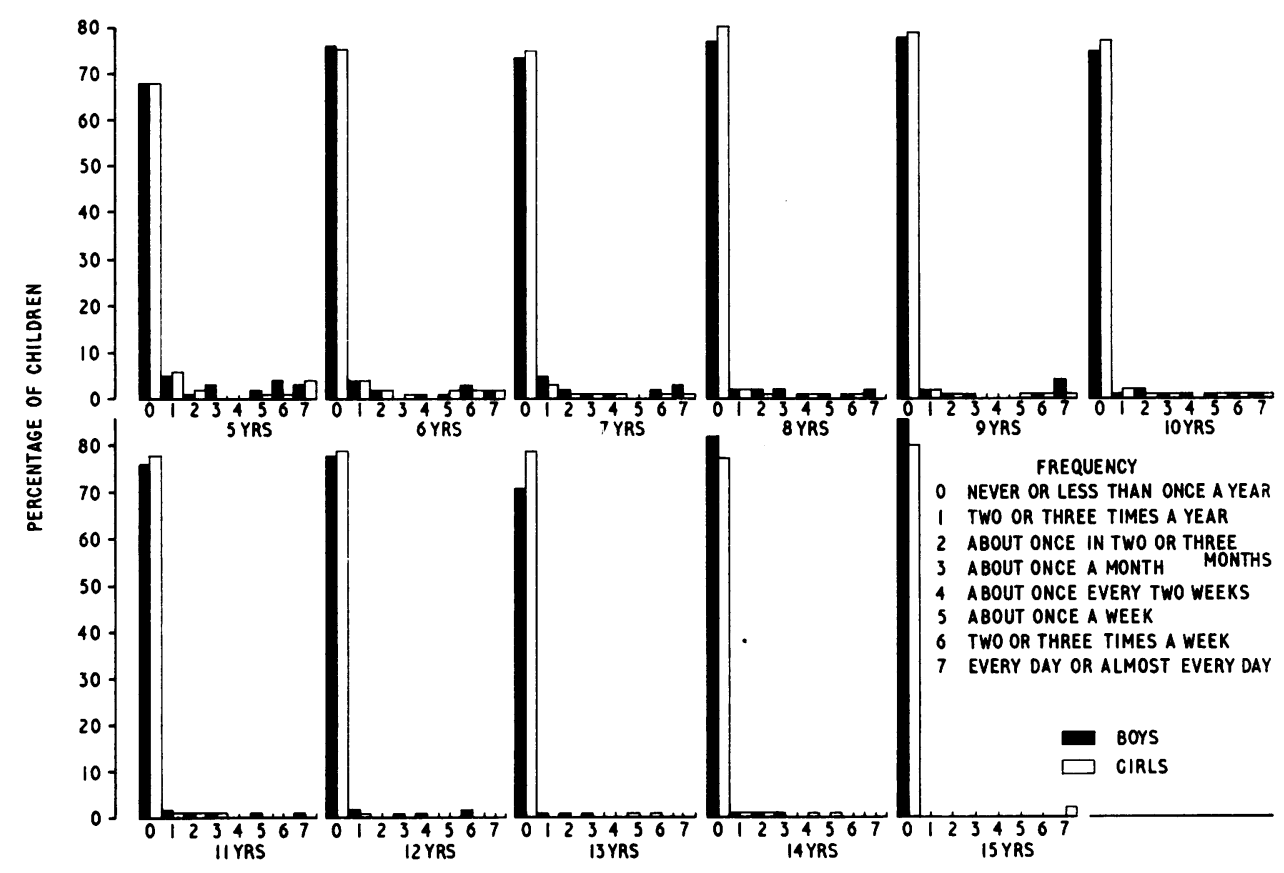

FIG. 1. Frequency distribution of bedwetting by age and sex for a sample of normal school children.

Bornholm is a model of its kind, wrote of survey methods that 'the most important purpose of such research is to provide reliable figures for the expectation of hereditary mental diseases in the general population' (Fremming, 1951).

The classical contribution of epidemiology in this sphere, however, has been the concept of accident proneness. The origin of this term can be traced back to 1919 when Greenwood and Woods, in their report to the Industrial Fatigue Research Board, suggested that the observed frequency distributions of accidents in a group of factories fitted best mathematically with the hypothesis of initially unequal liabilities to accidents rather than to pure chance or to a bias in the direction of individuals who had already sustained at least one accident (Greenwood and Woods, 1919). Further work tended to substantiate this notion of 'accident liability', but in 1926 Farmer and Chambers transmuted a statistical into a psychological concept, defining 'accident proneness' as 'a personal idiosyncrasy predisposing the individual who possesses it in a marked degree to a relatively high accident rate' (Farmer and Chambers, 1926). Though the evidence has never established a dichotomy between individuals who are and are not accident-prone, nonetheless, as Adelstein has commented, the concept 'was seized upon as the open sesame to all accident problems' by many subsequent workers who were impressed by the more speculative assumptions of psychosomatic medicine (Adelstekn 1952). That a more rigorous application of the cen cept may still prove rewarding has been demonstrat d recently by Smart and Schmidt (1962). Basing theiro work on the suggestion that patients with psycho- + somatic illnesses tend to experience morbid tension, and seek release by physical action which is often ill-considered, they argued that such patients would therefore tend to be involved comparatively frequently in all forms of accidents, including traffico accidents. From a group of 271 male hospital patients in Ontario with an unequivocal diagnosis of 3 peptic ulcer, they ascertained that 135 possessed driving licences, and that this subgroup did not differo in social or demographic essentials from either the remaining ulcer patients or from the male population of the province. They then compared the ageadjusted traffic-accident rates for the 135 index cases 3 with those of male car drivers in the general popula-i tion. Table III shows that this group experienced a읙 significantly higher rate of accidents than average, and so constituted a high-risk group.

COMPLETING THE CLINICAL PICTURE In the use of epidemiological techniques as aids to the completion, N or extension, of the clinical picture of mental disease, $N$ perhaps the most interesting development in this 
TABLE III

TRAFFIC ACCIDENTS OF MALE PEPTIC ULCER PATIENTS AND EXPECTED ACCIDENTS 1 JANUARY 1956-30 JUNE 1959

\begin{tabular}{lcccc} 
Year & Observed & Expected & Pooled $x^{2}$ & $P$ \\
\hline 1956 & 12 & 8.382 & & \\
1957 & 10 & 8.440 & & \\
1958 & 11 & 7.856 & & \\
1959 (6 months) & 6 & 3.632 & 4.0366 & $<0.05$ \\
Totals & 39 & 28.310 & 4.0366
\end{tabular}

The pooled $x^{2}$ had one degree of freedom. A $x^{2}$ of $5.1066(P<$ $0.025)$ was obtained by using the observed and expected frequencies of both accident and non-accident drivers in the sample.

country has been the new look taken at the general practitioner under the National Health Service. The crude statistics of the age-sex distribution of neurotic illness as obtained from hospital data and from general practice (Fig. 2) indicate the dimensions of the problem of neuroses in the community (Kessel and Shepherd, 1962).

Study of the nature of the clinical and social phenomena exhibited by these patients (only a small minority of whom are ever referred to a psychiatrist) constitutes a major task for the future. So does their outcome, for whereas prognostic studies of the major forms of psychiatric illness are well-established, our knowledge of the natural history of the minor disorders is still in its infancy. Meanwhile evidence is accumulating to suggest that psychological and social factors can affect the outcome of some established physical disease whose

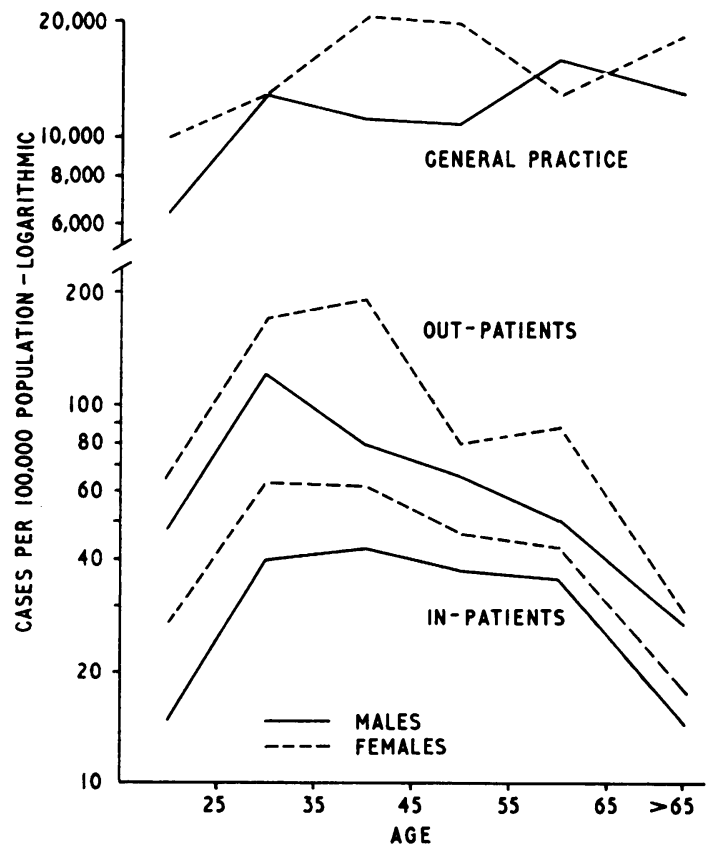

FIG. 2. Age prevalence of neurosis studied di:ring one year. course is known to differ widely from case to case (Querido, 1959). Recently, for example, Rutter has conducted an anterospective study of a sample comprising 80 cases of established peptic ulceration followed up for six months after their discharge from hospital in-patient care (Rutter, 1963). During their stay in hospital observations were made on the patients' physical condition and radiological status by a physician; at the same time the psychosocial variables were assessed independently by the psychiatrist and psychiatric social worker. After six months the patients were re-examined by all three observers independently. Surprisingly, outcome could not be correlated with any of the somatic or social factors but Tables IV and V show that affective features present at the initial psychiatric examination were significantly related to the patient's state after six months, whether this was assessed either by the presence of ulcer pain or by incapacity for work.

\section{TABLE IV}

ASSOCIATION BETWEEN ANXIETY AT INTERVIEW AND PAIN

\begin{tabular}{llccc} 
Pain & $\begin{array}{l}\text { Anxiety } \\
\text { None }(A)\end{array}$ & Mild $(B)$ & $\begin{array}{l}\text { Moderate or } \\
\text { Severe }(C)\end{array}$ & Total \\
\cline { 2 - 5 } & No. & No. & No. & No. \\
\hline None & $22(57.9 \%)$ & $12(50 \cdot 0 \%)$ & $5(31 \cdot 3 \%)$ & 38 \\
I & $12(31.6 \%)$ & $6(25.0 \%)$ & $1(6.3 \%)$ & 19 \\
II & $4(10.5 \%)$ & $6(25.0 \%)$ & $10(62.5 \%)$ & 20 \\
Total & 38 & 24 & 16 & 78
\end{tabular}

$x^{2}=13.358, p<0.001, c=0.33(2 d . f .$, ccmbining groups $\mathbf{B}$ and $\mathrm{C}$ for calculation of chi-square).

\section{TABLE V}

ASSOCIATIO: BETWEEN ANXIETY AT INTERVIEW AND WORK INCAPACITY AT FOLLOW-UP

\begin{tabular}{lccc} 
& None & Present & Total \\
\hline None & 31 & 17 & 48 \\
Present & 4 & 11 & 15 \\
Total & 35 & 28 & 63 \\
Not applicable & 5 & 12 & 17
\end{tabular}

$x^{2}=6.532,2$ d.f., $p<0.02$.

Extending the clinical picture to include the subclinical, or 'incipient' cases with declared illness raises particular difficulties in psychiatry. How important this problem can be is well shown in the sphere of mental subnormality when intelligence test results are compared with clinical findings. In the study of Stockholm children cited by Penrose, for example, a group of 300 children excluded from ordinary schools on the ground of feeble-mindedness, was examined with a modified version of the Binet- 


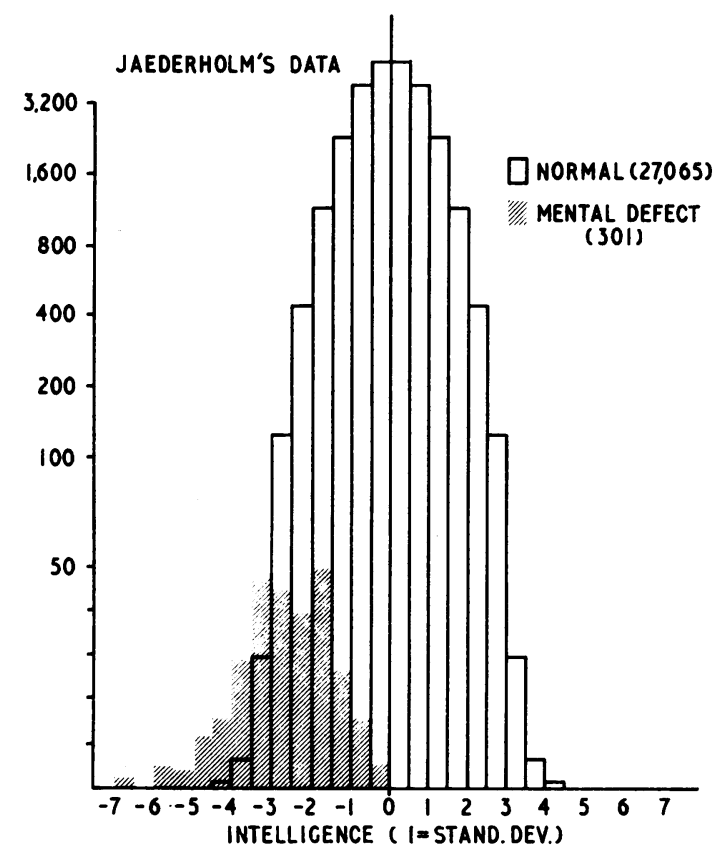

FIG. 3. Distribution of intelligence (Pearson and Jaederholm, 1931).

Simon test (Penrose, 1949). A sample of the normal school population was similarly examined. It was shown that the distribution of intelligence scores was quite continuous, with no indication of a natural boundary between the normal and the defective children. There was a close correlation (about +0.8 ) between the test scores and the clinical diagnosis of feeble-mindedness, but the correspondence was by no means perfect; had the ascertainment of mental deficiency been made on test scores rather than clinical examination, a somewhat different group would have been selected as abnormal.

The clinical picture can also be extended by comparisons between mental illness in different environments as by the description of the so-called exotic psychiatric disorders (Arieti and Meth, 1959). The possibilities of this approach have been explored by Murphy in his careful study of the urban distribution of mental illness in Singapore (Murphy, 1955). By relating the rates of mental hospital admission to areas of residence in terms of defined census tracts, he was able to show, in accordance with expectation, that positive relationships existed, some tracts being associated with much higher rates than others. Unlike his predecessors working in the Occident, however, Murphy did not find the highest rates of illness in the densely populated lower class slum districts. Again, when the residential areas were classified by cultural and ethnic characteristics, it emerged that contrary to findings elsewhere, geographic mobility correlated positively with manic-depressive disorder and negatively with schizophrenia. The key to these discrepancies, Murphy suggested, lay in the speciab socio-cultural features of Singapore which dis- 0 tinguish it from the pattern of most western cities Emphasizing the importance of the supportive culture which exists in the Singapore slum areas, he commented: 'There is a tendency in the West to. think of the slums as being populated by people whos have no ambition and have made no effort to geto out of them; in Singapore one might say that a con등 siderable proportion of the slum dwellers are theres. precisely because they have ambition-at least theo ambition to leave their native land in search of something better'. With regard to the unexpected ${ }^{\text {s }}$ distribution of the functional psychoses, he suggested $\overrightarrow{0}$ that the association found in other societies between high rates of schizophrenia and lack of cultural sup- $\omega$ port is understandably absent in Singapore, because "what causes or at least is linked to the rise in the schizophrenia rate is not the absence of culturalin support but the efforts of both society and the individual to regain or retain such support'. Eniv Singapore, where the stranger must contend with $\mathrm{An} V$ attitude of laissez-faire indifference, 'the evidences, says Murphy, 'suggests that an effective type of breakdown may be encouraged when the individual lacks the support of a surrounding culture and is not led to make an effort to assimilate'.

DELINEATION OF SYNDROMES A W.H.O. expert呑 committee (W.H.O., 1960) has recommended that this method be employed in all prevalence surveys ono the grounds that symptoms constitute the most easily standardized and measurable units of observation, and that knowledge of their distribution in $\frac{\mathrm{Q}}{\mathrm{O}}$ populations, independent of the charting of formal illness, leaves the way open for new discoveries. $\overrightarrow{\overrightarrow{0}}$ There is, however, an understandable reluctance on 3 the part of clinically trained psychiatrists to revert to purely symptomatic levels of description perhaps for the reason that Lewis has advanced: 'It is humiliating because it throws us back to the infancy of medicine'? (Lewis, 1961).

The recording of enumerated symptoms has proved most valuable so far in screening techniques, $\widehat{\varrho}$ employed mainly where large numbers have to be examined rapidly, as in induction procedures응 (Brodman, Erdmann, Lorge, Deutschberger, and $>$ Wolff, 1954). The use of a similar technique in an area prevalence survey has been described by MacMillan (MacMillan, 1957). A more promising or field for the mapping of new syndromes, however, is $N$ that of child psychiatry, where an established noso- 
logy is still lacking and the clinician relies less on symptoms than on signs of morbidity, particularly on disturbances of behaviour. Case identification is here more difficult in that it may depend, not so much on the observation of intrinsically abnormal behaviour, as on exaggeration of normal traits or the persistence of certain kinds of behaviour beyond the appropriate stage of development. To this extent, pathological disturbance may be equated with deviation from the norm, and the significance of any observed item of behaviour cannot be assessed without some knowledge of its frequency by individual age groups. Thus in a current British research project, the Buckinghamshire Child Health Survey, information has been gathered on a sample of 6,000 normal school children, and also on child guidance clinic attenders with known psychiatric disturbance (Shepherd et al., 1964b). The data, collected from questionnaires completed by parents and teachers, cover the occurrence and frequency of most commonly recognized symptoms, and also provide for the rating of various characteristics on a simple three-point scale. In this way, a picture is being built up of behavioural norms for this population, and the significance of the least common characteristics tested by comparison with the child guidance sample. Observed clustering of symptoms or uncommon characteristics can then provide a basis for the delineation of syndromes or abnormal patterns of behaviour.

COMMUNITY DIAGNOSIS With this type of study epidemiology enters the realm of public health and medical administration. Though its more immediate concern is likely to be with the planning of health services, the diagnosis of health and disease in whole communities has prevention as its ultimate goal. In this context, the survey of mental deficiency carried out over thirty years ago by $E$. $O$. Lewis can still be regarded as a model (Lewis, 1929). He took six geographical areas of England and Wales, each with a population of about 100,000 , and of widely differing type; three were urban and three rural, and they included a metropolitan suburb, a mining area, and a northern cotton town. Lewis was able to show that they were representative of the country as a whole in respect of such characteristics as social class and occupation, incidence of treated mental disorder, and ascertained mental deficiency. He then carried out in each area a survey of adult mental deficiency based on the reports of all available medical and social agencies, together with a screening of all schoolchildren. This latter, the most important part of the investigation, was carried out in three stages. First, the teachers in each school were asked to pick out the children of each age whose school work and general performance was poorest; about $15 \%$ of the whole school population was sorted out on this basis, so that there was no possibility of any significant number of retarded children being missed. Secondly, all these children were then submitted to group intelligence tests, which were supervised and scored by Lewis's assistants. Thirdly, all children whose scores on the group tests suggested a degree of mental retardation were examined individually by Lewis, using both intelligence tests and medical inspection. In the infants' departments, where group tests were inapplicable, $6 \%$ of the most backward children were examined individually. By these methods Lewis obtained a total prevalence rate for the six areas surveyed of 8.57 per thousand, a figure which still commands substantial agreement.

Where sufficient knowledge has been established a psychiatric condition, like any other, can be identified by screening procedures, and prophylactic measures can be introduced by the public health authorities. In the case of phenyleketonuria, for example, it has already proved possible for 124 British local health authorities at the request of the Ministry of Health to undertake the routine screening of infants aged 4-6 weeks and so to identify 39 cases from more than 650,000 tests; the possibility of treating these early cases with low phenylalanine diets then opens the way to preventive action (Medical Research Council, 1963). Unfortunately few psychiatric disorders are sufficiently well defined for large-scale, rational prophylactic or therapeutic measures to be feasible and most community studies have been concerned chiefly with the prevalence of mental ill health. The results of these surveys are least equivocal when the patient's condition is clearly identified by contact with a medical or social agency.

In Britain the National Health Service has led to so wide a coverage of the population by general practitioners that the extent of such conspicuous morbidity can be estimated from their returns. The amount of illness is not inconsiderable. A study of our own, for example, has recently shown that the reported one-year period prevalence rate for adult psychiatric illness reported by some 80 practitioners in the London area was as high as 140/1,000 (Shepherd, Cooper, Brown, and Kalton, 1964a). These estimates, however, represent only a fraction of the reported rates of medically inconspicuous morbidity. Here the investigator is compelled to employ an operational definition of mental ill health and to examine whole populations or samples of them by questionnaire or interviews: often he undertakes a large, extensive survey supplemented by a smaller intensive study. For the purpose some workers adopt a pragmatic approach with reliance on the subject's reports, supplemented by direct questioning. In a 
study of a new housing estate, for example, Martin et al. interviewed a sample of 750 families at home, using a check-list of symptoms: $22 \%$ of the adults admitted to 'nerves', $17 \%$ to 'depression', $12 \%$ to sleeplessness, and almost as many to undue irritability (Martin, Brotherston, and Chave, 1957). Other workers assume that there is a scale along which mental health or personality can be placed and measured; the authors of the mid-town Manhattan project (Srole, Langner, Michael, Opler, and Rennie, 1962), for example, quote with approval the view ... 'that an emotional adjustment exists on a quantitative continuum and that trained psychiatrists or psychologists are able to place an individual in his position on this continuum ...' (Wittson and Hunt, 1951). On either assumption the results are disconcerting. The families on the housing estate exhibited at least one symptom in $35 \%$ of cases; of the midtown residents only $18.5 \%$ were deemed mentally 'well'. It must be concluded either that mental ill health approaches the rule or that the criteria by which it is assessed are inadequate. At present the operational criteria of individual investigators differ so widely as to render comparative studies in place or time more useful than attempts to chase the chimera of 'true' prevalence.

Comparison between the prevalence rates of mental ill health in more than one area usually goes with a search for ecological correlates, ranging from relatively simple factors like overcrowding to complex indices of social structure like those employed by Leighton in N. America (Leighton, 1959) and Loudon in S. Wales. Comparisons over time are harder to come by but the results of Essen-Möller's forthcoming second survey of the overt and latent mental disability in south Sweden should be of particular interest (Essen-Möller, 1961). Mention must also be made of the large anterospective study of Wilner and his colleagues who examined the effect of the quality of housing on mental and physical health by a three-year follow-up of 300 families moved from slum to superior accommodation with a control group of 300 slum families; they succeeded in demonstrating that determination and half a million dollars can prove the obvious, but their work stands as a monument to the practical use of epidemiology in social research (Wilner, Walkley, Pinkerton, and Tayback, 1962).

HISTORICAL STUDIES As a means of demonstrating changes in the character or distribution of illness the use of the historical method in psychiatry has been limited until recent years. With the help of this method it is possible to analyse time trends to determine, above all, whether the amount of mental illness has altered and whether it has been affected by therapeutic or other measures. Anecdotal studies like those of Haeser (1882) and Hecker (1859) on the dancing manias of the Middle Ages are descriptively important but their value is much enhanced whew reliable statistics are also available. Hare, fof example, from a study of contemporary records and clinical descriptions, was able to plot the spread op general paresis across Europe, and to adduce $\frac{+}{2}$. certain amount of evidence supporting the hypow thesis of a neurotropic strain of spirochaete originat ing in northern France at the end of the fifteent century (Hare, 1959). He was also able to make use of statistical data to examine more recent trends? thereby demonstrating a steady decline in the prevalence of general paresis which has long antedated modern methods of treatment.

To the long-standing controversy on the putative increase of mental disorder, Goldhamer and Marshaf made a useful contribution by comparing mental hospital admission rates in Massachussets over a $\overrightarrow{00}$ interval of 100 years (Goldhamer and Marshal 1953). They found that the nineteenth and twentiet century age-specific rates were radically different; i⿱⺈ the earlier period there was a relatively high cons centration in the 20 to 50 age group, whereas in 7 恳 more recent period the majority of patients admifed were in their fifties and sixties. On the evidence the suggest that while a large part of the seemingan crease was due to a growing tendency to admiete hospital patients with mental disorders associated with the senium, some of the increment mightobs attributed to a true rise in the incidence of thisese conditions, especially cerebral arteriosclerosis.

In a different field, Halliday has studied the patterns in the incidence and distribution of certaig 'psychosomatic' disorders over the first half of the century (Halliday, 1949). He found evidence of marked increase in the incidence of peptic ulce among males, but not among females, so that the sex ratio for this group of disorders had changet considerably during the period under review. Cong versely, for diabetes there had been a marked increase among females, but not among males. Over a periỡ of 50 years the male/female ratio for deaths ascribed to this disease had fallen from 2 to $0 \cdot 5$. Halliday postulated that such striking changes in the sex distribution of disease must be associated with some corresponding changes of male and female psychö. social roles in our society.

STUDIES OF HEALTH SERVICES IN ACTION The perspective obtained from historical studies can of service in the assessment of current health services and the prediction of future needs. The prese debate on the future of British mental hospitals, for example, has been largely inspired by the recordeg 
fall in mental hospital residents over the past decade. According to one prediction the need for beds will have fallen about $40 \%$ by 1975 , largely because of an anticipated run-down of the population of chronic hospital inmates (MacLay, 1963). As this decline has coincided approximately with the introduction of tranquillizing drugs, some workers have claimed a causal association between the two events. That this is not necessarily so has been shown by the static picture obtained from individual institutions which had enjoyed the benefits of a major programme of administrative reform, with favourable consequences for the bed state, before the advent of tranquillizers (Shepherd, Goodman, and Watt, 1961). Such figures suggest that the social concommitants of drug therapy play an important part in affecting the flow of patients from hospital.

Attempts to examine directly the workings of the mental health services in action have been surprisingly few. Recently, however, Lawrence has made an operational study of the emergency procedures in London by concentrating on the social determinants of admission to a metropolitan observation ward (Lawrence, 1963). She was able to obtain relevant information about not only a group of patients but also a sample of the $20 \%$ of people who were referred to the mental welfare department without further action being taken. Her findings indicate that however important the medical aspects of the case both the breakdown in tolerance which initiated referral and the decision of the D.A.O. to take action were also affected strongly by social and administrative pressures and by the attitudes and beliefs of contiguous figures in the immediate environment.

\section{FUTURE PROSPECTS}

No survey, however brief, of the past and present status of psychiatric epidemiology can be complete without some reference to its future. At a recent American conference devoted to the future of psychiatry hopes were pinned to the development of giant electronic digital computers 'permitting the posing of questions and obtaining of answers which were never dreamed of in the past' (Pasamanick, 1962). It would seem to be more realistic to recognize that the questions are already with us and that most of the answers are more likely to come from human than from mechanical brains. Nor is it necessary to accept the complementary American prophecy of 'the continued application of human ignorance and error to research method and analysis and interpretation of data', provided the clinical and the social investigator can be imbued with a viewpoint which was clearly outlined by Sir James Spence:
'His main task is to place the phenomena (of disease) in temporal and in quantitative relationships with each other. This leads him to know the course of a disease as it may be expected commonly to occur. His next task is to determine the variation from that course, and to find correlations between these variations and aetiological factors or alternative treatments. When possible he uses statistics to express these variations. He uses statistical estimates of variations also in designing the extent of his study. If the disease under study is one which varies little in its course he limits his number of examples. . . . $\mathrm{He}$ thus comes to know disease as a predictable sequence of events, and the knowledge gained becomes the basis, the only basis, by which the underlying process of disease in the living patient can be rationally interpreted' (Spence, 1954).

Spence was talking here about clinical science but his summary of its logic might be transposed verbatim to what is now being called clinical epidemiology. This discipline can and should supplement and expand the psychiatrist's traditional concern with the individual patient. 'Psychiatry', as Ødegaard has insisted, 'is forced to study groups and populations because it deals with individuals, not in spite of that fact' (Ødegaard, 1962).

The authors would like to acknowledge the sources of several tables and figures in the text. They are: Dr. K. Rawnsley (Table I), Pediatrics (Table II), the Editor and publishers of the Journal of Psychosomatic Research (Tables III, IV, and V), of the Journal of Mental Science (Figure 2), and of Annals of Eugenics (Figure 3).

\section{REFERENCES}

Adelstein, A. M. (1952). J. roy. stat. Soc. A., 115, 354.

Arieti, S., and Meth, J. M. (1959). In American Handbook of Psychiatry, edited bv S. Arieti, vol. 1, ch. 27, p. 546. Basic Books, New York. Blum, R. H. (1962). Milbank mem. Fd Quart., 40, 253.

Böök, J. A. (1961). In Causes of Mental Disorders: A Review of Epidemiological Knowledge, 1959, p. 14. Milbank Memorial Fund, New York.

Brodman, K., Erdmann, A. J., Lorge, I., Deutschberger, J., and Wolff, H. G. (1954). Amer. J. Psychiat., 111, 37.

Brown, J. A. C. (1961). Freud and the Post-Freudians, p. 124. Penguin Books, London.

Brugger, C. (1931). Z. ges. Neurol. Psychiat., 133, 352.

Cohen, B. H., Lilienfeld, A. M., and Sigler, A. T. (1963). Amer. J. publ. Hlth, 53, 223.

Crombie, D. L. (1963). Lancet, 1, 1205.

Douglas, J. W. B., and Mulligan, D. G. (1961). Proc. roy. Soc. Med., $54,885$.

Durkheim, E. (1951). Suicide: a Study in Sociology. Translated by J. A. Spaulding and G. Simpson. Free Press, Glencoe, Illinois.

Essen-Möller, E. (1961). In Comparative Epidemiology of the Mental Disorders, (Proc. 49th A.M. Amer. Psychopathogical Ass.), edited by P. H. Hoch and J. Zubin., p. 1. Grune and Stratton, New York.

Faris, R. E. L., and Dunham, H. W. (1939). Mental Disorders in Urban Areas: an Ecological Study of Schizophrenia and other Psychoses. University of Chicago Press.

Farmer, E., and Chambers, E. G. (1926). Industr. Fatigue Res. Bd. Rep. No. 38. H.M.S.O., London.

Fremming, K. H. (1951). The Expectation of Mental Infirmity in a Sample of the Danish Population (Occasional Papers on Eugenics, no. 7), p. 12. Cassell, London. 
Freud, S. (1955). Group Psychology and the Analysis of the Ego. In Complete Psychological Works, vol. 18, p. 69. Hogarth Press, London.

Frost, W. H. (1927). In Public Health and Preventive Medicine, vol. 2, p. 163. Nelson, London.

Ginsberg, M. (1956). In On the Diversity of Morals, p. 157. Heinemann, London.

Goldberger, J. (1914). Publ. Hlth Rep. (Wash.), 29, 1683.

(1927). De Lamar Lectures, p. 128. Williams and Wilkins, New York.

_- Wheeler, G. A., and Sydenstricker, E. (1920). Publ. Hlth Rep. (Wash.), 35, 2673.

Goldhamer, H., and Marshall, A. (1953). Psychosis and Civilization, 2nd ed. Free Press, Glencoe, Illinois.

Greenwood, M. (1935). Epidemics and Crowd-Diseases, p. 133. Williams and Norgate, London.

Report No. 4. H.M.S.O., London.

Gruenberg, E. M. (1957). In Explorations in Social Psychiatry, edited by A. H. Leighton, J. A. Clausen, and R. N. Wilson, p. 201. Tavistock Publications, London and New York.

Haeser, H. (1882). Lehrbuch der Geschichte der Medicin, 3rd ed. Fischer, Jena.

Halliday, J. L. (1949). Psychosocial Medicine. Heinemann, London.

Hare, E. H. (1959). J. ment. Sci., 105, 594.

Hecker, J. F. C. (1859). The Epidemics of the Middle Ages, translated by B. G. Babington, 3rd ed. Trübner, London.

Hersov, L. A., and Rodnight, R. (1960). J. Neurol. Neurosurg. Psychiat., 23, 40.

Hinkle, L. E., and Wolff, H. G. (1957). In Explorations in Social Psychiatry, edited by A. H. Leighton, J. A. Clausen, and R. N. Wilson, p. 105. Tavistock Publications, London.

Kessel, N., and Shepherd, M. (1962). J. ment. Sci., 108, 159.

Knobloch, H., and Pasamanick, B. (1960a). In Mental Retardation. Proceedings of the 1st international conference on Mental Retardation, edited by P. W. Bowman, and H. V. Mautner, p. 182. Grune and Stratton, New York.

(1960b). Pediatrics, 26, 210.

Kreitman, N. (1961). J. ment. Sci., 107, 876.

Lawrence, A. R. le V. (1963). Ph.D. Thesis, University of London.

Leighton, A. H. (1951). Bull. Johns Hopk. Hosp., 89, 73.

- (1959). My Name is Legion. Basic Books, New York.

Lewis, A. J. (1961). In Comparative Epidemiology of the Mental Disorders, edited by P. H. Hoch, and J. Zubin, p. 229. (Proc. 49th A.M. Amer. Psychopathological Ass.), Grune and Stratton, New York.

Lewis, A. J. (1962). Yale J. biol. Med., 35, 62.

Lewis, E. O. (1929). Board of Education and Board of Control Mental Deficiency Committee Report, pt. 4. H.M.S.O., London.

Lin, T-Y, and Standley, C. C. (1962). The Scope of Epidemiology in Psychiatry. Public Health Papers No. 16. W.H.O., Geneva.

MacLay, W. S. (1963). Amer. J. Psychiat., 120209.

MacMillan, A. M. (1957). Psychol. Rep., III, 325. Monograph suppl. 7. Southern Universities Press.

Malzberg, B. (1940). Social and Biological Aspects of Mental Disease. State Hospital Press, Utica, New York.

Mangus, A. R., and Dager, E. Z. (1959). In Epidemiology of Mental Disorder, edited by B. Pasamanick. Amer. Ass. adv. Sci. Publ., no. 60 , p. 39 . Washington, D.C.

Marshall, T. H. (1963). In Sociology at the Crossroads and other Essays, p. 41. Heinemann, London.

Martin, F. M., Brotherston, J. H. F., and Chave, S. P. W. (1957), Brit. J. prev. soc. Med., 11, 196.
Medical Research Council (1963). Brit. med. J., 1, 1691.

Meyer, A. (1912). J. Amer. med. Ass., 58, 911.

Milbank Memorial Fund (1950). Epidemiology of Mental Disordē New York.

Milbank Memorial Fund. (1961). Causes of Mental Disorders: $\overline{\bar{a}}$ Review of Epidemiological Knowledge, 1959. New York.

Morris, J. N. (1957). Uses of Epidemiology. Livingstone, Edinburg

Murphy, H. B. M. (1955). Unpublished manuscript.

Ölegaard, Ö. (1962). Proc. roy. Soc. Med., 55, 831.

Paffenbarger, R. S. (1961). J. chron. Dis., 13, 161 Paffenbarger, R. S. (1961). J. chron. Dis., 13, 161.
Parsons, R. P. (1943). Trail of Light. Bobbs-Merrill, Indianapolis, Ne@
York.

Pasamanick, B. (1962). In The Future of Psychictry (Proc. 51st meeting Amer. Psychopatholog:cal Ass. 1961) edited by R. H. Hock art J. Zubin p. 216. Grune and Stratton, New York.

Pearson, K., and Jaederholm, G. A. (1931). On the inheritance mental disease. Ann. Eugen. (Lond.), 4, 362.

Penrose, L. S. (1949). The Biology of Mental Defect, p. 22. Sidgwi\& and Jackson, London.

(1952). On the Objective Study of Crowd Behaviour. Lew London.

Pollock, H. M. (1925). State Hosp. Quart., 10, 1934.

Querido, A. (1959). Brit. J. prev. soc. Med., 13, 33.

Rawnsley, K. (1963a). M.R.C. Committee on the Epidemiology Psychiatric Illness. Unpublished.

- (1963b). Lecture delivered to Social Psychiatry and Psych $\vec{\theta}$ therapy Section of R.M.P.A., 1963. Unpublished.

Reid, D. D. (1960). Epidemiological Methods in the Study of Mentä Disorders. Public Health Papers No. 2, pps. 8 and 15. W.H.O Geneva.

Robinson, W. S. (1950), Amer, sociol. Rev., 15, 351.

Rosanoff, A. (1917). Psychiat. Bull., 2, 109.

Rutter, M. (1963). J. psychosom. Res., 7, 45.

Ryle, J. A. (1948). Changing Disciplines, p. 12. Oxford Universit Press, London.

Shepherd, M., Cooper, B., Brown, A. C., and Kalton, G. (196/a) Brit. med. $J$. , in the press.

- Goodman N and Watt, D. C. (1961). Comprehens. Psyc 2, 11.

-, Oppenheim, A. N., and Mitchell, S. (1964b). Unpublished Cata.

Siler, J. F., Garrison, P. E., and MacNeal, W. J. (1917). Third Repoxt of the Robert M. Thompson Pellagra Commission of the Ne York Postgraduate Medical School and Hospital, New Yor

Smart, R. G., and Schmidt, W. S. (1962). J. psychosom. Res., 6, की

Spence, J. (1954). Lect. sci. Basis Med., 2, 5.

Srole, L., Langner, T. S., Michael, S. T., Opler, M. K., and Re T. A. C. (1962). Mental Health in the Metropolis: the Midfow Manhattan Study. McGraw-Hill, New York.

Strömgren, E. (1950). Congrès International de Psychiatrie: Vit Psychiatrie Sociale, p. 155. Hermann, Paris.

Taylor, F. Kräupl, and Hunter, R. C. A. (1958). Psychiat. Quar 32, 821.

Thomas, C. L., and Gordon, J. E. (1959). Amer. J. med. Sci., 238, 36

Trotter, W. (1942). Instincts of the Herd in Peace and War, 2nd eg్ Scientific Book Club, London.

Wilner, D. M., Walkley, R. P., Pinkerton, T. C., and Tayback, M (1962). The Housing Environment and Family Life. Johrg Hopkins Press, Baltimore.

Wittson, C. L., and Hunt, W. A. (1951). Amer, J. Psychiat, 107, 58

World Health Organization. (1960). Eighth Report of the Exper Committee on Mental Health. Wld Hlth Org. techn. Re Ser., no. 185.

Zilboorg, G. (1936). Amer. J. Psychiat., 92, 1347.

Zubin, J. (1963). Unpublished manuscript. 